\title{
Catheter in Antrochoanal Polyp: Functions Intact
}

\author{
Amol Hekare, Mohan Jagade, Vitthal D. Kale, Devkumar Rengaraja, Radhika Sonate, Karthik Rao
}

Department of ENT, Grant Government Medical College and Sir JJ Groups of Hospital, Mumbai, India

Email: amolhekare15@gmail.com

How to cite this paper: Hekare, A., Jagade, M., Kale, V.D., Rengaraja, D., Sonate, R. and Rao, K. (2017) Catheter in Antrochoanal Polyp: Functions Intact. International Journal of Otolaryngology and Head \& Neck Surgery, 6, 59-64.

https://doi.org/10.4236/ijohns.2017.65008

Received: March 29, 2017

Accepted: August 25, 2017

Published: August 28, 2017

Copyright $\odot 2017$ by authors and Scientific Research Publishing Inc. This work is licensed under the Creative Commons Attribution International License (CC BY 4.0).

http://creativecommons.org/licenses/by/4.0/

\begin{abstract}
The general rule to follow in nasal pathology is to intervene "as extensive as required and as limited as possible". There are various surgical methods described in the literature for the removal of Antrochoanal polyp that are refractory to medical treatment. However, these methods fail to restore and maintain the optimal physiology of the nose thus reducing the quality of life post operatively. Here in this article, we describe a relatively easy, safe and cost effective method of complete removal of the Antrochoanal polyp with the use of simple rubber catheters. It negates the need for sophisticated instruments and also helps in restoring the physiological function of the nose effectively as the nasal mucosa is left undisturbed.
\end{abstract}

\section{Keywords}

Antrochoanal Polyp, Catheter

\section{Introduction}

Antrochoanal polyp (ACP) is a benign inflammatory lesion that arises from the mucosa of the maxillary sinus antrum. It further widens the antrum and reaches the nasal cavity and expands posteriorly to the choana. Nasal obstruction is the main symptom of these patients. Usually, surgery is commonly indicated treatment for ACP, endoscopic resection being the popular method. Though, being commonly employed, it has its own drawback of having a steep learning curve and when done by untrained hands may land in catastrophic complications. Other methods such as, simple avulsion of the polyp has a high rate of recurrence due to incomplete removal. Whereas, the Caldwell-Luc procedure is associated with serious damage to the maxillary and dental growth centres. Here, in this article we describe a technique of complete removal of the polyp with the aid 
of simple rubber catheter/infant feeding tube without the assistance of endoscope.

\section{Method}

The surgery is done under general anesthesia with all aseptic precautions. The patient is made to lie supine and in a reverse trendelenburg position. Painting and draping of the patient is done. The nasal cavity is packed with $4 \%$ lignocaine + adrenaline soaked roller gauze to achieve decongestion and this helps in shrinkage of the inferior turbinate which plays a vital role in passage of the simple rubber catheter.

Two simple rubber catheters or infant feeding tubes are negotiated through the nasal cavity-one passing above the polyp and exiting through the choana and the other passing through the floor of the cavity below the polyp exiting through the choana Figure 1(a), Figure 1(b). Care must be taken to pass the open end of the catheter through the nasal cavity. The two rubber catheters are removed from the oral cavity which is kept opened with the aid of a self-retaining mouth gag. A knot is tied on the blind end of the catheter at the nasal end in such a fashion that they don't untwine Figure 2(a), Figure 2(b). These knotted catheters are pulled back into the nasal cavity in such a fashion that the knot remains anterior to the polyp. Once the knotted catheter is placed perfectly at the anterior end of the polyp, a freer's elevator is introduced medial to the catheters and the polyp in such a fashion that the elevator is in contact with the knotted catheter and it holds them in place preventing them from slippage. Then with a gentle pull through technique, with simultaneous movement of the freer's supporting the knot, the polyp is gently dragged towards the choanal end Figure 3(a), Figure $3(\mathrm{~b})$. Caution has to be exercised while dragging it posteriorly to avoid

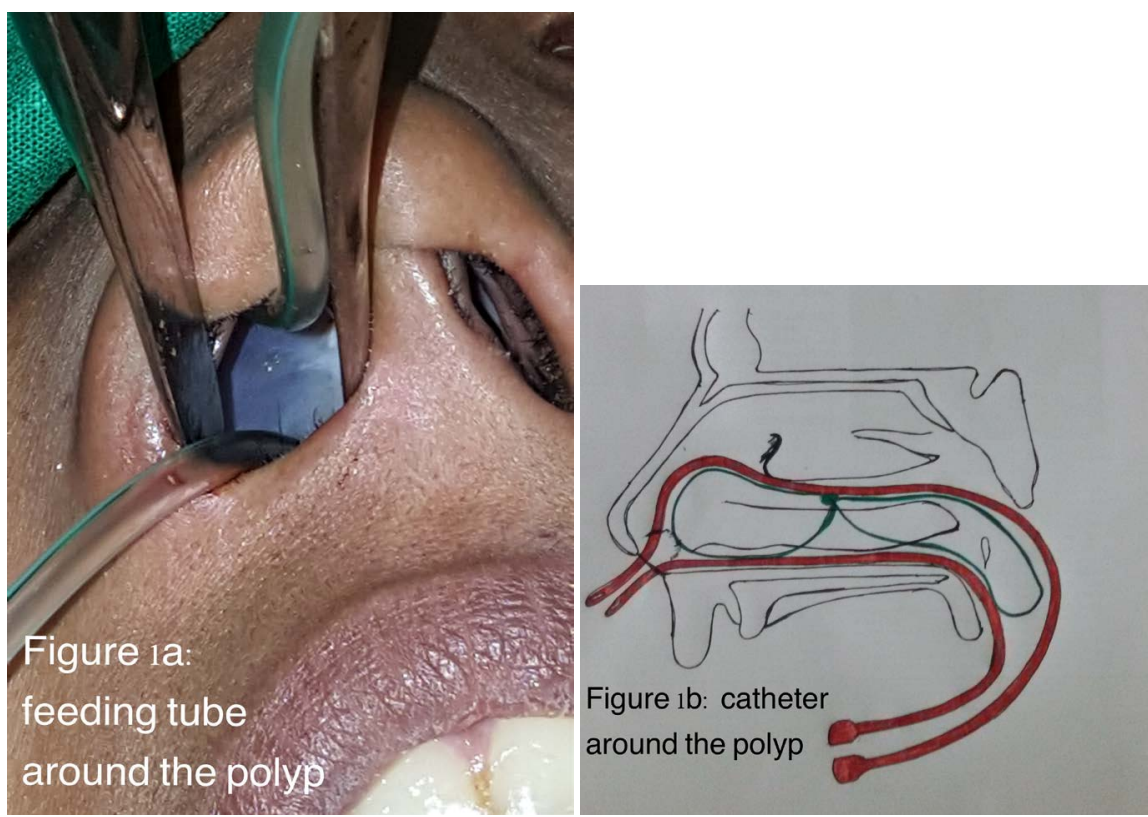

Figure 1. (a) (b) Showing feeding tube negotiated around nasal polyp. 

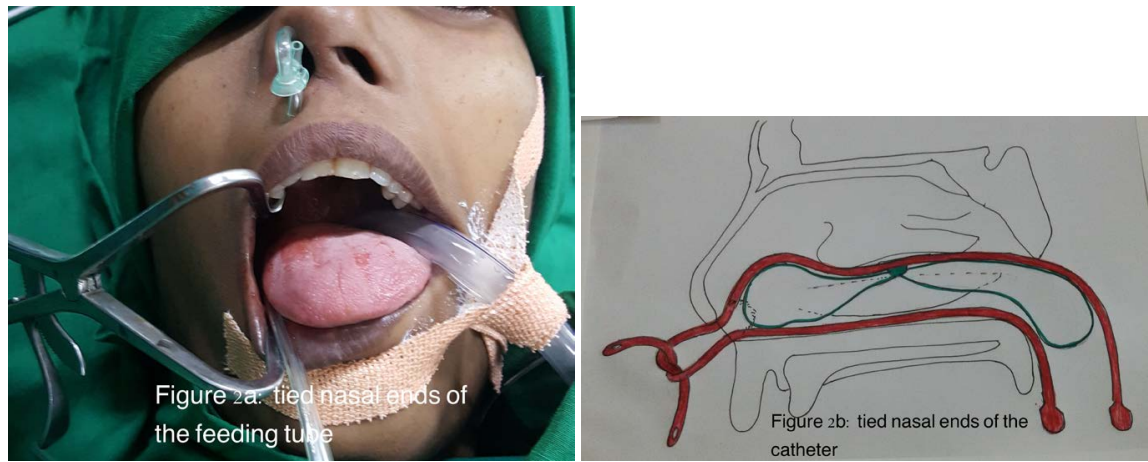

Figure 2. (a) (b) Showing tied Nasal end of feeding tube.
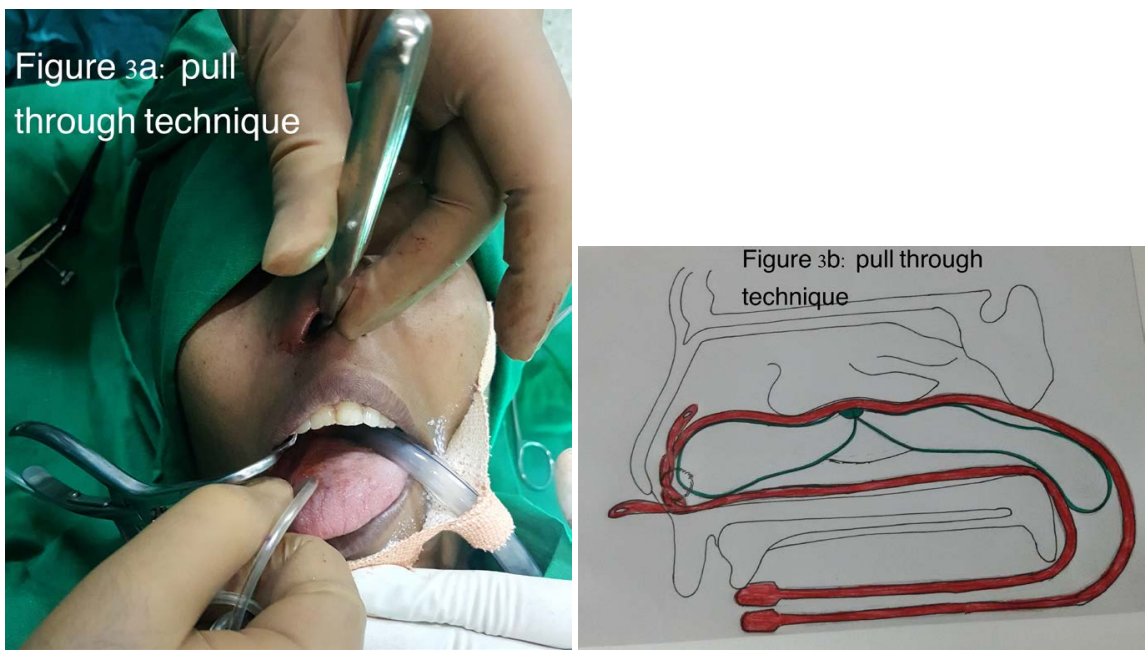

Figure 3. (a) (b) showing gentle pull through technique

polyp avulsion at the antral end and to remove it intact with the antral part of the polyp. The tri-lobed polyp is delivered from the oral cavity Figure 4.

The polyp when removed completely with all its attachments results in minimal bleeding. The nasal cavity is examined with the aid of a head light to ensure complete removal of the polyp. The same thing can also be checked with a 0 degree and 30 degree nasal endoscope. Later the maxillary and nasal cavity is packed with a netcel soaked in framycetin ointment which is removed after 24 hrs. The histopathology examination was consistent with the inflammatory pathology of Antrochoanal polyp Figure 5.

\section{Discussion}

AC polyp is an inflammatory polypoidal growth of maxillary sinus mucosa which enters the nasal cavity and grows towards the posterior choana. Fredrik Ruysch and Zuckerkandl were the first to report the case of AC polyp, but it was Professor Gustav Killian who described it for the first time and named it as killian's polyp [1].

The exact pathophysiological mechanism of the AC polyp is unknown. Many theories have been put forward for this. Among these, most accepted theory of 


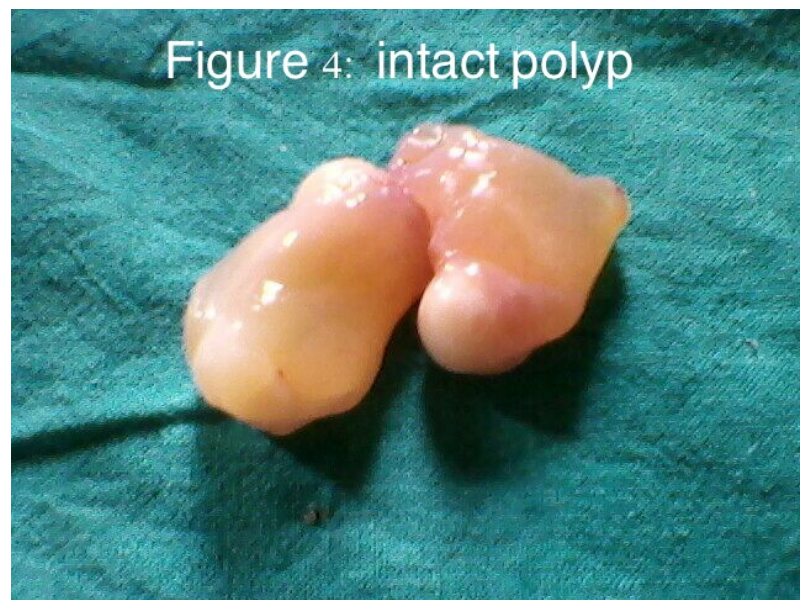

Figure 4. Intact polyp.

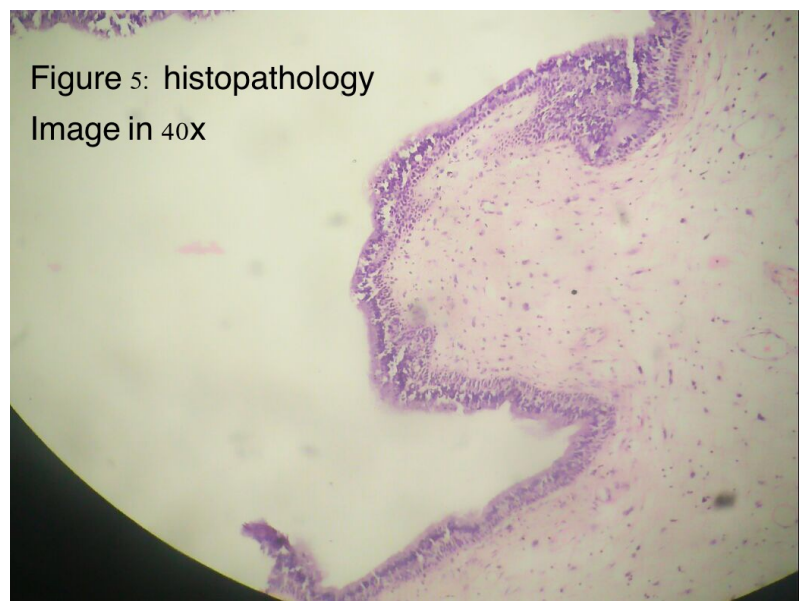

Figure 5. Histopathology image.

AC polyp formation is acinous mucous gland blockage. The repeated infection of maxillary sinus mucosa causes acinous mucous gland blockage that lines the maxillary antrum leading to AC polyp formation. AC polyp develops within the antrum and then exits through the natural or accessory ostium, forming Trilobed AC polyp of which-one part is in antrum, one in the nasal cavity and the other in the choana. The stalk of the AC Polyp that is present at the natural or accessory ostium is nothing but the thin wall of the cyst. The formation of Ac polyp is a vicious cycle which is due to chronic maxillary sinusitis and infection that hamper the antral ventilation, leading to acini blockade.

Macroscopically, AC polyp has cystic and solid part; cystic part fills the antrum and solid part protrudes through the ostium into nasopharynx. Microscopically, AC polyp shows a central cystic cavity surrounded by a homogeneous oedematous stroma with few cells [2].

The AC polyp is unilateral. The presenting symptoms of AC polyp is nasal obstruction, nasal drainage, rhinorrhea, snoring, headache, mouth breathing, epistaxis, anosmia, halitosis, dyspnea, dysphagia, dysphonia and nasal pruritis, 
Out of which nasal obstruction and nasal discharge are the most common presenting symptoms [3].

For the management of AC Polyp a careful history and a complete clinical examination is a must. The anterior rhinoscopy examination reveals a smooth, pale mass which is insensitive to touch and probe can be passed all around the polypoidal mass and the posterior rhinoscopy shows the choana filled with polyp. A CT PNS (coronal, axial, sagittal cuts of $2 \mathrm{~mm}$ ) plays a pivotal role in the diagnosis as well as paves a roadmap for the surgery.

AC polyp can be managed both medically and surgically. Although, medical treatment has become unpopular these days, the heart of medical management is to control repeated maxillary sinus infection which prevents acinous block. The topical and systemic steroids are the documented type of medical treatments for the AC polyp. Though, topical steroids fail in eliminating the polyp they reduce them in size. Systemic steroid therapy is equally effective as simple polypectomy and it may serve as "Medical Polypectomy" [4].

Surgery plays the main stay of treatment in AC polyp. There are various techniques described ranging from Simple avulsion, Caldwell-Luc to Endoscopic sinus surgery in AC polyp resection. All these methods have their own merits and demerits. Simple polypectomy with a snare results in incomplete removal of the polyp as the antral part remains untouched leading to recidivism. Thus, due to a large recurrence rate, this technique is now obsolete [5].

In Caldwell-Luc technique a sublabial incision is taken at the level of gingivolabial sulcus to create a window and enter the maxillary sinus, thus creating an anterior antrostomy. Caldwell-Luc approach gives a good surgical exposure and hence, the possibility of removing the polyp completely is higher [6]. However, the procedure has its share of complications such as cheek anaesthesia due to accidental severing of inferior orbital nerve, cheek swelling, nasolacrimal duct injury and sublabial fistula. Osteomyelitis of maxilla has also been reported but is very rare. It also carries the risk of hampering teeth development in children [7].

Functional endoscopic sinus surgery (FESS) is the most widely used technique in Nasal surgeries these days, but due to its cost availability and steep learning curve its use has been limited. To overcome this obstacle in places with dearth of facilities the technique of using rubber catheter for surgical removal of the AC polyp has been tried in this study. Use of rubber catheter has shown a considerable decrease in intraoperative and postoperative bleeding which is one of the most challenging complications faced by surgeon during other surgeries like Caldwell-Luc and FESS. FESS is a sophisticated technique which needs the assistance of highly advanced appliances. The main factor to limit use of Endoscopic sinus surgery is requirement of experienced endoscopic surgical skills and the failure to preserve healthy mucosa which results in dryness and subsequent crusting which is very troublesome in the post-operative period. Infection, CSF leak, anosmia, injury to eye and its adnexa are the deadly side effects which are not uncommon. Lamina papyracea is very thin bone when fractured during En- 
doscopic Sinus Surgery causes intra-orbital bleeding, fat herniation and External Ocular Muscle (EOM) injury. Sphenopalatine artery, ethmoidal artery, and internal carotid artery are always at danger during Endoscopic sinus surgery leading to catastrophic complications. Injury to the Optic nerve in sphenoid sinus can cause permanent blindness [8]. All the above mentioned complications can be avoided by our method of using rubber catheter for AC Polyp resection. As rubber catheter is flexible structure it can be very easily negotiated through nasal cavity with minimal chances of injury to the adnexal structure thus minimizing the complications and better postoperative outcome. Our technique is safe, economical and atraumatic and preserves the mucosa, though it requires requisite expertise and a thorough knowledge of anatomy.

\section{Limitation}

In cases with extensively large polyps the passage of rubber catheters may be a challenging task. Though, we didn't face such a trouble across post adequate decongestion. Recurrence is a possibility if incompletely removed.

\section{Conclusion}

The technique of AC polyp removal with the aid of simple rubber tube is a very cost effective, safe method which restores the physiological function of the nasal mucosa and helps in maintaining the milieu interieur of the nose. Although it requires expertise, it is an easily learnable skill and can be employed even in remote and peripheral setups where the availabilities of sophisticated instruments are limited.

\section{References}

[1] Killian, G. (1906) The Origin of Choanal Polypi. The Lancet, 168, 81-82. https://doi.org/10.1016/S0140-6736(01)32583-7

[2] Maldonado, M., Martínez, A., Alobid, I. and Mullol, J. (2004) The Antrochoanal Polyp. Rhinology, 42, 178-182.

[3] Orvidas, L.J., Beatty, C.W. and Weaver, A.L. (2001) Antrochoanal Polyps in Children. American Journal of Rhinology, 15, 321-325.

[4] Lildholdt, T., Fogstrup, J., Gammelgaard, N., Kortholm, B. and Ulsoe, C. (1988) Surgical versus Medical Treatment of Nasal Polyps. Acta Oto-Laryngologica, 105 140-143. https://doi.org/10.3109/00016488809119457

[5] Al-Mazrou, K.A., Bukhari, M. and Al-Fayez, A.I. (2009) Characteristics of Antrochoanal Polyps in the Pediatric Age Group. Annals of Thoracic Medicine, 4, 133. https://doi.org/10.4103/1817-1737.53353

[6] Schramm, V.L and Effron, M.Z. (1980) Nasal Polyps in Children. The Laryngoscope, 90, 1488-1495. https://doi.org/10.1288/00005537-198009000-00010

[7] Woolley, A.L., Clary, R.A. and Lusk, R.P. (1996) Antrochoanal Polyps in Children. American Journal of Otolaryngology, 17, 368-373. https://doi.org/10.1016/S0196-0709(96)90068-X

[8] Rombout, J. and de Vries, N. (2001) Complications in Sinus Surgery and New Classification Proposal. American Journal of Rhinology, 15, 363-370. 
Submit or recommend next manuscript to SCIRP and we will provide best service for you:

Accepting pre-submission inquiries through Email, Facebook, LinkedIn, Twitter, etc. A wide selection of journals (inclusive of 9 subjects, more than 200 journals)

Providing 24-hour high-quality service

User-friendly online submission system

Fair and swift peer-review system

Efficient typesetting and proofreading procedure

Display of the result of downloads and visits, as well as the number of cited articles Maximum dissemination of your research work

Submit your manuscript at: http://papersubmission.scirp.org/

Or contact ijohns@scirp.org 